\title{
A GROUNDED THEORETICAL STUDY ON THE INFLUENCE MECHANISM OF VERBAL ABUSE BY TEACHERS
}

\author{
Jinnan Li, \& Yuheng Zhang \\ Faculty of Education, Beijing Normal University (China)
}

\begin{abstract}
Language violence by teachers has a serious negative impact on students' mental health. In this study, 16 primary and middle school students were interviewed in depth and qualitative research was conducted on the interview data using grounded theory. It is found that the language violence of teachers has the characteristics of harmfulness, persistence and coercion. Its manifestation mainly includes three kinds: Openness and directness, Openness and indirectness and private directness. The attribution of language violence in teachers mainly includes teacher attribution, self-attribution and task attribution. From the results, the language violence of teachers will have a serious negative impact on students' psychology, but sometimes it will also play a promoting role in some students. Based on the paradigm model of grounded theory, the paper also constructs a theoretical model of the influence mechanism of teacher verbal abuse. According to the model, the interaction between the internal personal evaluation system and the attribution system determines the degree of influence of teacher's verbal violence on students.
\end{abstract}

Keywords: Verbal abuse by teacher, primary and secondary school students, influence mechanism, grounded theory.

\section{Introduction}

The teacher's verbal violence referred to in this study is a negative verbal behavior pattern in which teachers have a negative impact on students' physical and mental development through reprimand, insult and abuse in education and teaching activities. It is also a kind of emotional and spiritual abuse. (Zhibin Zhang \& Yue Zhang,2013) Based on the investigation of primary and middle school students, this paper focuses on the influence mechanism of teacher language violence and tries to make a simple description and explanation of the influence mechanism of teacher language violence. The research tries to answer the following questions: (i) according to students, what is teacher's language violence, that is, what are the characteristics of teacher's language violence? (ii) Under specific circumstances, how does language violence occur? (iii) What are the effects of language violence on students and how to respond to it?

Primary and secondary school students are in the development period of values and ideology, and teachers as key figures will have an important impact on their inner shaping. In particular, teachers play a central role in students' self-evaluation, and students reflect on their own values according to teachers' attitudes, comments and evaluations. In other words, children who lack internal standards of self-evaluation tend to judge their academic ability, achievement and self-efficacy based on teacher evaluations. Therefore, teachers have the responsibility to strengthen their language cultivation, so that their language will not only become the carrier of knowledge, but also become the motivation for students to realize their own value. (Qiran Wang \& Yang Li,2019) If teachers ignore this responsibility, once teachers use verbal violence against students, students will suffer negative effects that cannot be reversed and made up for. (Li Tan \& Yunxiang Fan,2017)

Verbal violence refers to the use of verbal abuse, slander, contempt, ridicule and other insulting discriminatory language, resulting in the mental and psychological assault and damage of others, which belongs to the category of mental injury. The language violence of teachers is the language violence that teachers impose on students.

Studies on language violence by teachers can be divided into the following three stages according to the research emphasis.

The first stage is the general description stage, and the research mainly focuses on the end of the 20th century. At this stage, most of the studies used statistics to describe the prevalence of language violence among teachers. OLWEUS, for example, studied 2,400 Norwegian students in grades 6-9 using the peer nomination method in a 1996 study. The study showed that at most $5.2 \%$ of students were 
subjected to verbal abuse by teachers. (Olweus D,1996) But CASARJIAN's study of 700 north American students from low-income backgrounds paints a different picture. Thirty-four percent of the students reported at least six incidents of teacher language violence, while 11 percent reported at least 31 incidents during the school year. (Casarjian BE,2000)

The second stage is the longitudinal connection study, mainly focusing on the study from 2001 to 2015. The main purpose of this phase of research is to explore the longitudinal relationship between teacher language violence and children's development at different stages. Among them Mara Brendgen was a key figure in this period. He tracked 399 children (177 girls) from kindergarten through fourth grade for seven years. The results showed that language violence by teachers was a highly stable phenomenon for 15 percent of children. Children with antisocial behavior and attention problems in kindergarten are more likely to be abused by teachers in primary school. Language violence by teachers is significantly associated with children's subsequent delinquency and academic difficulties. (Brendgen M, Wanner B \& Vitaro F ,2006) The effect was not transitory. After further research, Brendgen concluded that there was also a significant link between verbal violence by teachers and behavioural problems at the age of 23. Especially for girls who experienced language violence from teachers as children, their chances of obtaining a high school diploma are low. (Brendgen M, Wanner B \& Vitaro F ,2007)

After 2016, the third stage is the in-depth research stage. The research in this stage focuses on the specific situation of teachers' language violence and tries to make an in-depth investigation of teachers' language violence in a dynamic and micro process. In 2016, Brenda Geiger interviewed 60 sixth graders in Israel, asking them to make free statements, so as to understand the real inner world of children under teachers' language violence. In the face of teachers' language violence, students often choose to keep silent because of teachers' authority and fear of retaliation, so they are unwilling to report the situation to their parents and school leaders. Although they remain silent, they tend to vent by means of internal monologues. After being abused by teachers, students became indifferent to teachers' comments and began to lose interest in school. (Geiger B,2017) In 2018, Eriyanti observed the specific interaction process between teachers and students from the perspective of power imbalance. Through a critical discourse analysis of the verbal expressions between teachers and students, the author finally summarizes seven patterns of language violence used by teachers in the specific teaching process: rejection, accusation, undervaluation, ridicule, coercion, threat and anger. (Eriyanti RW,2018)

Generally speaking, compared with the survey of parents and teachers, it is obviously more instructive to let students make their voices heard from the perspective of students. Because students are the most important stakeholders and the direct victims of teachers' language, their views on language violence deserve our attention. In addition, only when students can freely express their experiences in school and talk about the incidents that violate their rights in school, can they be most effectively protected by the adult world, thus safeguarding respect, dignity and other legitimate rights and interests. Therefore, this study intends to conduct an in-depth exploration of the inner world of primary and middle school students in the form of in-depth interviews, hoping to guide them to use their own language to convey the most authentic views on teachers' language violence.

\section{Methods}

To solve the above problems, this study decided to adopt the method of grounded theory. As an important research path of qualitative research, it is widely used in the field of social science. "The purpose of research is to generate theories, and theories must come from empirical sources; Research is a process of systematically collecting and analyzing data, discovering, developing and testing theories. The research results are theoretical representations of reality. A theory discovered through a systematic process of data collection and analysis is called grounded theory. (B. Glaser \& A.L. Strauss, 1968) The reason why grounded theory is adopted in this study to discuss "the influence mechanism of teacher language violence" is that this method can reflect the inner world of students to the greatest extent.

\subsection{Sample recruitment}

Due to the low cognitive development level and language expression ability of students in the lower grades of primary schools, and considering the investigation fact that junior middle school is the worst-hit area for teachers' language violence, the interviewees of this study are mainly for primary and junior middle school students in grades 4 to 6 . Since grounded theory does not specify the sample size, in principle sampling can be stopped as soon as theoretical saturation is reached. Therefore, 16 primary and secondary school students in the preliminary investigation stage were selected theoretically (namely primary and secondary school students who had experienced language violence by teachers). There are 3 people in grade 4, 2 people in grade 5,2 people in grade 6,5 people in grade 1 and 4 people in Grade 2. 


\subsection{Procedure}

2.2.1. Open coding. The purpose of open coding is to identify the genera and their attributes and dimensions by "tagging" the interview data for further analysis. In this step, in-depth interview is mainly used to collect data. In the open coding, this study insists on logging in the concept of personal localization in the original materials, so as to create four initial categories of characteristics, manifestation, attribution and results of language violence of teachers after the tagging analysis of the interview materials of four interviewees.

2.2.2. Axial coding. In the spindle coding stage, 6 interviewees were asked the same 7 questions above. But different from open coding, spindle coding pays more attention to a more profound analysis of the six categories that have been abstracting in the process of open coding. The researchers conducted in-depth analysis on a particular genus at a time, hoping to enrich the correlation of such subspecies as much as possible.

2.2.3. Selective coding. The third step is to select the code, that is, to find a core genus from the generalized genera, so as to form a connection among the genera, construct the initial paradigm model of teacher language violence, and then establish a storyline consistent with the paradigm model.

\section{Results}

\subsection{Characteristics of language violence by teachers}

3.1.1. Harmfulness. On the surface, teachers' verbal violence seems to have a more insignificant impact on students than corporal punishment. But in the course of the study, it was found that sometimes it was more harmful to students than corporal punishment. Especially for those students who are introverted and sensitive in mind, a bad word from teachers will often cause long-term psychological troubles and serious harm to the development of students. For example, student D: " I don't like being told that I am not good by my classmates, let alone by my teacher. The teacher is the person we are closest to. What she says affects how my classmates think of me."

3.1.2. Persistence. The language violence of teachers also has the characteristics of persistence. Teachers ignore the principal status of students, disregard their personal dignity, even if the occasional vicious words, will also cause lasting damage to the students' spiritual world. For example, student $\mathrm{F}$ said in an interview, "Teachers' words have a negative impact on self-confidence. I don't want to meet teachers and classmates outside. Because I can't forget the teacher's abuse, even after a long time".

3.1.3. Coercion. In the eyes of students, the language violence of teachers is also characterized by coercion. No matter how to emphasize the subject status of students in education, in the real teaching environment, the relationship between teachers and students is still dominated by the manager and the managed. Especially for the physical and mental development of primary and middle school students, teachers are absolutely perfect leaders in their hearts. It is with the help of such a "superior leader" image that teachers make their language violence with strong coercion. "He stood on the platform, high above me, pointing at me all the time and telling me how stupid I was, and I could only sit in my seat and not argue, because he was the teacher." Student B's narration reflects the forceful characteristics of improper language of teachers due to the infiltration of teachers' authority.

\subsection{Forms of language violence by teachers}

3.2.1. Openness and directness. According to the students' narration of teachers' language violence, the most common manifestation of teachers' language violence towards students is open and direct. That is, teachers in the public (mainly in the classroom) directly insult, abuse students. For example, teachers will directly insult and reprimand unruly students in class, and some even make public verbal attacks on students' hair styles and names.

3.2.2. Openness and indirection. The second type of language violence is the overt and indirect type. Compared with the first type, this type causes more obvious psychological harm to students. The so-called openness and indirection refer to the demeaning behavior of a teacher towards a student in public (mainly in class). For example, student H: "The teacher praised my desk mate's progress in study and said he was 100 times smarter than me in front of everyone." Another example is that a teacher talks to a student whose father has died, "Your father is gone, but you still don't study hard. " In this study, there are two main ways in which teachers use language violence against students by referring to other students or by referring to relatives of students to arouse students' family guilt. 
3.2.3. Private directness. The third form of teacher language violence is the private direct type. That is, the teacher engages in language violence in the environment where he is alone with the students. Compared with the first two forms, this kind of teacher's language violence has a mild impact on students. Some students even explicitly mentioned that the teacher said a lot of "uncomfortable words" to them in private chat, but expressed gratitude for the teacher's words, because they thought the teacher was in their good intentions.

\subsection{Attribution of teacher's verbal violence.}

The first is teacher attribution. In other words, students attribute the reason of language violence to teachers themselves. They believe that teachers often commit language violence due to bad mood, poor ethics or short temper. The second category is self-attribution. In other words, students attribute the language violence to themselves. Such students show extreme polarization in character. Optimists, with their broader mindset, often attribute the teacher's bad words to not trying hard enough. However, overly introverted students often attribute their teachers' language violence to their own abilities or talents due to their lack of sufficient confidence. The third category is task attribution. In other words, students attribute the language violence to the task itself. For example, student I: "The teacher asked me to do the problem on the blackboard, but I couldn't do it for a long time. The teacher finally told me to 'roll down'. But I thought the problem was too difficult. "

\subsection{The result of language violence by teachers}

3.4.1. Positive results. Teachers' language violence sometimes has a positive impact on students, which is rarely mentioned in the interview, but it also exists objectively. Although the democratic equality between teachers and students in teaching is strongly advocated now, strict criticism is the responsibility and authority of teachers as the traditional teacher ethics requirement in China. But the line between good words and bad words is not always clear. When the teacher's strict criticism goes too far and turns into verbal violence, students who believe in the teacher's traditional ethics still sometimes regard it as a means to motivate themselves. Some students said: "Sometimes the teacher said dirty words, but that's because the teacher wants us to do better."

3.4.2. Negative results. On the whole, the target of teachers' language violence is usually the students who have poor grades and are playful and active. In fact, even if teachers are changed, these students are still the target of language violence by new teachers. For these students, teacher language violence, often accompanied by insulting words, stigmatizes them as "not liked by the teacher." In the face of verbal attacks from teachers, most students experience extremely negative emotions. In the face of verbal violence by teachers, students sometimes use "crying" to express their hurt emotions, but many also choose "silence" to relieve the pain. Although they don't talk to their parents, other teachers or school leaders, they secretly curse the teachers who have hurt them. Even in extreme cases, they will act violently, such as slamming the door and running out of the classroom, breaking their own water glass and so on.

\subsection{The process mechanism diagram of language violence by teachers}

According to the paradigm model of teacher language violence, this study proposes the influence mechanism of teacher language violence as shown in figure 1. The author believes that there are two systems in students' minds that are related to the results of teacher's verbal violence: the personal evaluation system and the attribution system.

In the face of language violence by teachers, students will first evaluate their own personal evaluations. The external manifestation of language violence will affect the result of individual evaluation. When a teacher publicly engages in verbal violence against students in class, students will feel a sharp drop in their personal evaluation because they "lose face in the whole class". The overt and indirect ways of language violence are more likely to frustrate students than the overt and direct ways of language violence.

In addition to taking into account their own personal evaluation, students will also conduct attribution analysis on the teacher's verbal violence. Students who attribute the causes of language violence to their own optimists and to tasks are more likely to self-resolve their negative results. Compared with the students who attributed to the teachers themselves, introverts were more likely to develop the dark mentality of inferiority, negativity and anger. 
Figure 1. The influence mechanism of teacher language violence.

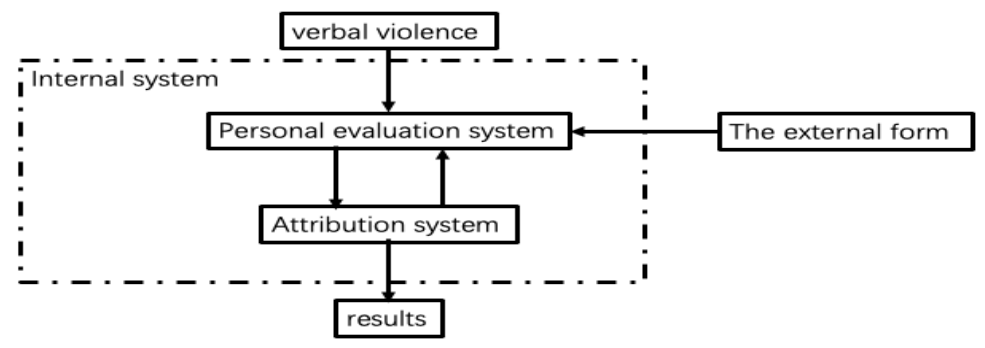

The interaction between individual evaluation system and attribution system contributes to the final step of the whole process of teacher's language violence -- the result of teacher's language violence. This result is sometimes shown by students' crying and violent resistance, but more often the result is invisible, hidden in their own hearts. We have no way of knowing whether it is good or bad, except to enter their inner world.

\section{Discussion and conclusions}

The purpose of this study is to discuss the characteristics, manifestation, attribution and results of teacher language violence through in-depth interviews, to establish a preliminary example model and principle of the mechanism of teacher language violence process that can be further tested in subsequent studies, and to generate a grounded theory of teacher language violence.

From the research results, the paradigm model established in this study is effective. It reveals the characteristics, manifestation, attribution and results of language violence by teachers, which is more in-depth and comprehensive than the quantitative research on the same topic. The important innovation of this study lies in the understanding of the influence mechanism of teacher's language violence from the perspective of the "victim" through the narration of students, although it is difficult to avoid the unobjective criticism in the research process. However, the author maintains that it is the students who are affected by the language violence of teachers, and their understanding and understanding of the whole process are the closest to the truth.

Through the research, we find that, faced with the abuse of teachers' language violence, students will initiate the personal evaluation system and attribution system internally, and explain each other through the internal system, so as to produce the final result that can affect students' psychology and behavior. These findings undoubtedly provide more research perspectives for the follow-up related studies.

\section{References}

Brendgen M, Wanner B, Vitaro F. (2007). Verbal abuse by the teacher during childhood and academic, behavioral, and emotional adjustment in young adulthood. Journal of Educational Psychology, 99(1),26-38.

Brendgen M, Wanner B, Vitaro F. (2006). Verbal abuse by the Teacher and Child Adjustment from Kindergarten Through Grade 6. PEDIATRICS,117(5),1585-1598.

Casarjian BE. (2000). Teacher psychological maltreatment and students' school-related functioning. Columbia : Columbia University.

Eriyanti RW. (2018). Power Gap as One of the Trigger of Verbal Abuses Committed by Teachers in Schools. International Journal of Instruction,11(1),368.

Geiger B. (2017). Sixth graders in Israel recount their experience of verbal abuse by teachers in the classroom. Child Abuse and Neglect,63,95-105.

Glaser, G., Barney. (1968). The Discovery of Grounded Theory: Strategies for Qualitative Research. Nursing Research ,17(4),377-380.

Li Tan,Yunxiang Fan. (2017). An Analysis of language violence about Physical Education Teachers. Sports Culture Guide, 11,135-139.

Wang Qiran, LI Yang. (2019). The Characteristics and Countermeasures of Primary School Teachers 'Verbal Abuse to Students: An Empirical Study based on Four Provinces and Cities in China. Journal of Education, Renmin University of China,02,51-65.

Zhang Zhibin, Zhang Yue. (2013). Attribution and Resolution of Language Violence in Moral education. Teachers. School party construction and ideological education,02,28-30. 